\title{
Management of Equine production and its environmental impact: the case of settlements in Buenos Aires (Argentina).
}

\section{Manejo de la producción equina e impacto ambiental: el caso de establecimientos en Buenos Aires (Argentina).}

\author{
Mariana M. Vaccaro ${ }^{a, b}{ }^{*}$, Alberto Garcia-Liñeiro ${ }^{a}$ and Alicia Fernández-Cirellib,c \\ a Universidad de Buenos Aires. Facultad de Ciencias Veterinarias .Cátedra de Salud y \\ Producción Equina Buenos Aires, Argentina. \\ b CONICET- Universidad de Buenos Aires. Instituto de Investigaciones en Producción \\ Animal (INPA) Buenos Aires, Argentina. Av. Chorroarín 280, C1427CWO, Ciudad \\ Autónoma de Buenos Aires, Buenos Aires, Argentina. \\ c Universidad de Buenos Aires. Facultad de Ciencias Veterinarias. Centro de Estudios \\ Transdisciplinarios del Agua (CETA). Buenos Aires, Argentina. \\ *Corresponding Author: mvaccaro@fvet.uba.ar \\ Facultad de Ciencias Veterinarias, Universidad de Buenos Aires
}

Recibido: 27 de febrero de 2017; Aceptado: 29 de marzo de 2017.

\section{ABSTRACT}

Equine production in Buenos Aires (Argentina) is 512847 heads. The equine production management is an important factor for the minimization of environmental effects. This management includes the implementation of good practices.

The aim of this paper is to characterize the equine production paddocks in Buenos Aires in terms of their management, and to evaluate the possible environmental impact they may generate. Sixteen paddocks have been characterized according to the sources of water supply, quantity and depth of the wells, breed, productive system, type and management of beds, type of feed, feeding practices, supplementation, other ration components and management. These are the first studies on environmental effects of equine production in Argentine.

Key Words: environment, equine production, management

\section{RESUMEN}

La producción equina en Buenos Aires (Argentina) es de 512847 cabezas. El manejo de la producción equina es un factor importante para la minimización de los efectos ambientales. Este manejo incluye la implementación de buenas prácticas. El objetivo de este trabajo es caracterizar los establecimientos de producción equina en Buenos Aires en cuanto a su manejo y evaluar el posible impacto ambiental que pueden generar. Se han caracterizado 16 establecimientos según las fuentes de abastecimiento de agua, cantidad y profundidad de los pozos, raza, sistema productivo, tipo y gestión de camas, tipo de alimentación, prácticas veterinarias, 
suplementos dietarios utilizados, y manejo de la alimentación. Este trabajo es el primer estudio sobre los efectos ambientales de la producción equina en Argentina.

Palabras clave: ambiente, producción equina, manejo.

\section{INTRODUCTION}

Equine production is widely distributed throughout Argentina with a total of $2,442,130$ heads (SENASA 2015). Argentina is internationally acknowledged as an equine producer par excellence, being among the top ten countries in the world. Production is distributed throughout 172,145 paddocks, being $16 \%$ pure-bred animals (MINAGRI 2014). Buenos Aires province concentrates $21.69 \%$ of the production.

The global studies on equine production management and its environmental effects is very scarce (Bott \& Greene 2013). As it is observed in other types of animal production, the production management is an important factor for the minimization of the environmental effects (Bott \& Greene 2013; Auer et al. 2013).

The productive management includes the implementation of good practices regarding the quality of the water suitable for animal consumption, the kind of nutrition and supplementation, the management of effluents, and the sanitary monitoring of the animals, among other variables (Fernández Cirelli et al., 2013). The water quality used for animal consumption is crucial since both the animals' health and nutrition depend on it (Fernández Cirelli et al., 2013).

The overfeeding of the equine and the excessive supplementation could be one of the main causes of environmental pollution. The phosphorus present in most of the nutritional supplements for sport equines, sent back to the environment in the manure, has the potential of a negative impact on it (Topliff 2002; Hainze et al. 2004; Westendorf et al., 2013; NRC 2007).

Poor management practices of dung could lead to an increase in the movement of sediments, nutrients and xenobiotics toward surface or groundwater, thus altering the resource quality.

The management of dung and beds has been the object of several investigations for the potential effect they can produce on the environment, mainly in the United States (Swinker et al 1995; Westendorf et al 2010a, b; Westerndorf 2012; Prokopy 2013; ).

This research had sport horses as the target population in the province of Buenos Aires, as this is the region with the largest number of heads in the country. It has to be pointed out that this is the first study of this kind in our country. The aim of this paper is to characterize the equine production facilities in Buenos Aires in terms of their management, and to evaluate the possible environmental impact they may generate.

\section{MATERIALS AND METHODS}

Study area: Establishments are located in the province of Buenos Aires (Figure 1) in a rural/urban interface area. A peripheral perimeter was established around the city of Buenos Aires starting in Escobar District, then Pilar, Exaltación de la Cruz, San Antonio de Areco, General Rodríguez, Lujan, Mercedes and General Las Heras districts. 
Survey: It was carried out in 16 paddocks with similar characteristics, mainly, training places for jumping horses, where the stable work routines, training, and health plan were homogenous. The floor of the boxes is earthen.

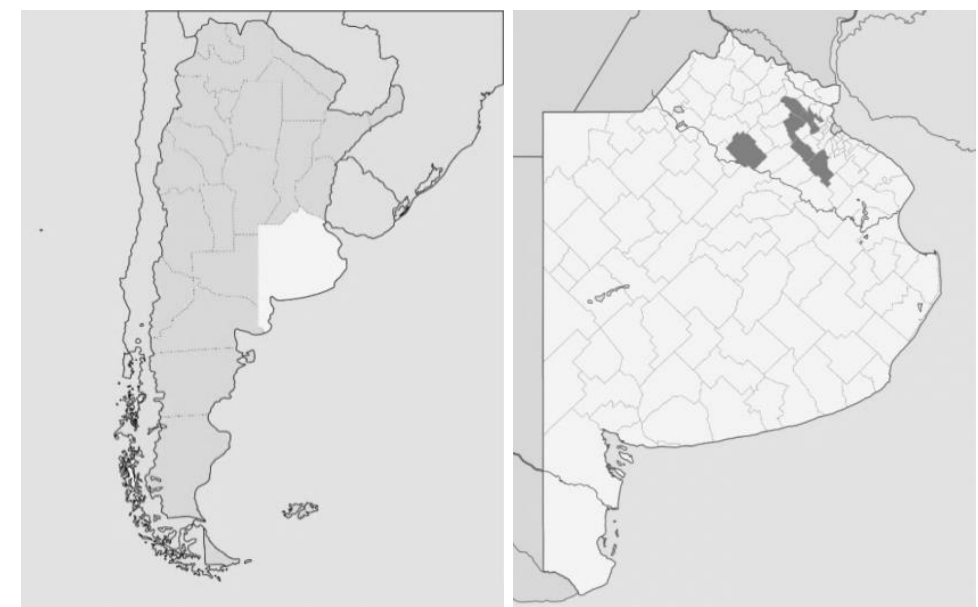

Figure 1: Study area of settlements in Buenos Aires (Argentina).

Through specific surveys, establishments have been characterized according to the sources of water supply (groundwater and surface water), quantity and depth of wells, breed (alfalfa, bundles, pellets, balanced feed), productive system, type of management of beds, type of feed, feeding practices, supplementation and management.

All the paddocks were visited, handed over the questionnaire to the person in charge and taken samples from the animals' feed, beds and drinking water.

Questions about the different management practices connected with the sport-equineproduction were asked:

- Drinking water source: ground or surface?

- Who do you receive counsel for the nutritional management of your animals from?

- Do you use feeders, bunks or mangers in order to minimize the food's contact with the ground, and thus, from rainwater?

- What kind of food do you feed your animals with?

- Do you use supplementation?

- How many hours a day do your animals spend in the box?

- What type of bed do you use? How do you manage the manure generated in the establishment?

- Nearby bodies of water: river - lagoon - stream? How far are they? At what depth is the water table?

- Under what kind of sanitary management is the paddock?

Samples: Water, feed and bed samples from the paddocks were recollected to evaluate the importance of these components in the quality of the dung in order to consider these sources both in the sanitary management of the equines and in the environmental risk the potential environmental risk of dung. The water samples $(\mathrm{N}=16) 500 \mathrm{ml}$ vol. approx. in polyethylene containers previously rinsed with distilled 
water, sealed without air chamber, taken to the laboratory refrigerated. They were acidified to preserve the analytes in $\mathrm{HNO}_{3}$ solution with $0.2 \% \mathrm{v} / \mathrm{v}$ at the time of collection. Once in the laboratory, they were filtered using $0.45 \mu \mathrm{m}$ nitrocellulose disposable filters if suspended solids were present.

The feed samples of alfalfa used as food were recollected in polyethylene bags (ca. $500 \mathrm{~g}$ approx. weight) and sealed.

The bed samples were recollected from the storage and were conditioned in plastic bags (ca. $500 \mathrm{~g})$ and sealed.

Determinations: Quantification of $\mathrm{As}, \mathrm{Pb}, \mathrm{Cd}, \mathrm{Cr}$, was performed by ICP-OES (inductively coupled plasma - optical emission spectroscopy) using a Perkin Elmer Optima 2000 DV. These elements were selected since their presence in large quantities in the water may be harmful to the animals' health (Fernández Cirelli et al., 2010; Asano et al. 2002); besides, in Argentina, arsenic is a toxic natural element very often found in ground and surface water (Smedley \& Kinninburgh 2002). This element comes from the pampean loess and it is present in large quantities in the ground and surface water of the Pampas plains (Farías et al. 2003). The $\mathrm{Cr}, \mathrm{Cd}$ and $\mathrm{Pb}$ are of anthropogenic origin.

For the equipment calibration, reference materials from the National Water Research Institute of Canada (NWRI) with certified content of all minor elements were used for calibration, verification and validation of the analytical method.

Feed and bed: Samples $(0.1 \mathrm{~g})$ were digested with conc. $\mathrm{HNO}_{3}(20 \mathrm{ml})$ and $15 \mathrm{~N}$ $\mathrm{H}_{2} \mathrm{SO}_{4}(10 \mathrm{ml})$. After complete oxidation, the samples were cooled and diluted to $50 \mathrm{ml}$ with deionized water.

\section{RESULTS AND DISCUSSION}

As regards the productive management, $88 \%$ of the analyzed paddocks were under the supervision of a veterinarian, while the other $12 \%$ were directly managed by the producer. The water sources come from groundwater in most cases - between 60 and 70 meters deep in most of the paddocks. This is consistent with the agricultural use of the water for animal production in Argentina since most of the water comes from groundwater (Farías et al. 2003).

As to feed management, most of the paddocks employ mangers to feed the animals (88\%); and $12 \%$ also use bunks. These methods allow for a proper feed management which guarantees the feed's safety and minimizes its lost and waste due to falls or trampling by animals.

The beds used in every facility are made of chips. Moreover, $25 \%$ of the facilities employ straw. All the establishments receive counsel from Veterinarians in order to balance the diet.

The feed used is predominantly alfalfa provided in bundle or pellets. Supplementation is used in all the paddocks; Concentrates are used in $100 \%$ of the paddocks, while $50 \%$ of paddocks employ oils, being the supply of electrolytes $(62.5 \%)$ and vitamins $(68.8 \%)$ lower. In addition, the use of balanced rations and growth promoters was recorded in only one paddock. The kind of supplementation given to the animals in these paddocks is similar to the one given in other parts of the world; however, in Argentina, the use of alfalfa equines feeding is traditional, unlike other parts of the world. 
For the beds, $25 \%$ of the studied establishments also incorporate straw. Most of them use feeders ( $87.5 \%)$, while $12.5 \%$ use bunks.

Regarding the training and daily working routines, the equines exercise each morning and are kept within stables, in $4 \times 4$ boxes, with food and drinking water inside.

It was observed, as a shared characteristic, that the discarded bed and manure were placed in open shaving storages, whose general clearance was carried out, on average, once every 45 days, leaving them exposed to the open air and rain during that period; and with the consequent and potential lixiviation of organic matter and pollutants.

The equines remain in the boxes from 10 to 18 hours. In the $30 \%$ of the paddocks, the animals are kept in the boxes for 14 hours. The time the animals stand in the box allows the observer to notice the abundant feces the equines produce on those beds that later are discarded in the external storages

The beds used in every facility are made of chips. Moreover, $25 \%$ of the facilities employ straw. The floor of the boxes is earthen, which allows for all the liquids filtered from the bed and droppings to go into the ground. Only $25 \%$ of the farms are close to a water body of water: lagoon (6.25\%); river $(6.25 \%)$ and stream $(12.5 \%)$.

Regarding the distance between the place and the water bodies: most of them $(75 \%)$ are $1 \mathrm{~km}$ away, while one of them is only $100 \mathrm{~m}$ away from a lagoon.

The depth of the water table was: $80 \mathrm{~m}(6.25 \%) ; 70 \mathrm{~m}(37.5 \%) ; 60 \mathrm{~m}(31.25 \%) ; 50$ $\mathrm{m}(12.5 \%) ; 40 \mathrm{~m}(6.25 \%) ; 30 \mathrm{~m}(6.25 \%)$. The health plan of every establishment consisted -as a basis- of a Coggins test every 2 months, vaccination against influenza every 3 months, vaccination against encephalomyelitis every 12 months, tetanus once a year, equine adenitis once a year. The deworming is carried out every 2 months with benzimidazoles-organophosphates, invermectin-prazicuantel and Equestpramox rotations, keeping this alternate order.

In the water samples, only As could be detected in the establishments 3 (25 $\mu \mathrm{g} / \mathrm{L}), 11(25 \mu \mathrm{g} / \mathrm{L})$, and $15(62 \mu \mathrm{g} / \mathrm{L})$, and $\mathrm{Pb}$ in establishments $3(26 \mu \mathrm{g} / \mathrm{L}), 10$ $(24 \mu \mathrm{g} / \mathrm{L})$, and $14(14 \mu \mathrm{g} / \mathrm{L})$. Nevertheless, concentrations determined are below the limits admitted for animal drinking in the argentine legislation (Ley 24051 Decreto 831/93). All other analyzed elements were below the detection limit (DL).

As is of natural origin in groundwater in large areas of Argentina (Smedley and Kinninburgh 2002), while $\mathrm{Pb}$ is of anthropogenic origin, as well as $\mathrm{Cr}$ and $\mathrm{Cd}$. These elements were analyzed since the equine farms studied are in a rural/urban interface area.

Bundle and bed were also analyzed and the results are shown in Table 1 and Table 2, respectively. As was only detected in samples of bundle from farms 2, 5, 10, 15 and 16 (Table 1). The high content in farm 5 is noteworthy and it will be further explored. Cd was found in $25 \%$ of establishments, while $\mathrm{Cr}$ was determined in $60 \%$ of establishments (Table 1). The concentrations found may be toxic for the animals, even though these elements are not still contaminating water tables. $\mathrm{Pb}$ was detected in $70 \%$ samples. The given values of $\mathrm{As}, \mathrm{Cd}$ and $\mathrm{Pb}$ are lower than the recommended by the 2002/32/CE Regulation issued by the European Parliament and Council (2002), which deals with undesirable substances in animal feed, except for one case of As in paddock 5. 
Table 1. Trace element analysis of bundle. Concentrations are expressed in $\mu \mathrm{g} / \mathrm{g}$. LG: Limits admitted for animal bundle in the European legislation (European Union 2002). Detection limit (DL).

\begin{tabular}{|c|c|c|c|c|}
\hline & \multicolumn{3}{|c|}{ BUNDLE } & \multirow[b]{2}{*}{$\mathrm{Pb}$} \\
\hline & As & $\mathrm{Cd}$ & $\mathrm{Cr}$ & \\
\hline $\mathrm{DL}$ & $<0.40$ & $<0.16$ & $<0.28$ & $<0.49$ \\
\hline LG & 4 & 1 & & 5 \\
\hline 1 & $<\mathrm{DL}$ & $<\mathrm{DL}$ & 0.81 & $<\mathrm{DL}$ \\
\hline 2 & 1.35 & 0.46 & 0.72 & $<\mathrm{DL}$ \\
\hline 3 & $<\mathrm{DL}$ & $<\mathrm{DL}$ & 4.88 & 0.51 \\
\hline 4 & $<\mathrm{DL}$ & $<\mathrm{DL}$ & 1.75 & $<\mathrm{DL}$ \\
\hline 5 & 9.47 & 0.39 & 4.45 & 0.99 \\
\hline 6 & $<\mathrm{DL}$ & $<\mathrm{DL}$ & $<\mathrm{DL}$ & $<D L$ \\
\hline 7 & 0.64 & $<D L$ & $<\mathrm{DL}$ & $<D L$ \\
\hline 8 & 0.51 & 0.32 & $<\mathrm{DL}$ & $<D L$ \\
\hline 9 & $<\mathrm{DL}$ & $<\mathrm{DL}$ & 0.68 & $<D L$ \\
\hline 10 & 1.10 & $<\mathrm{DL}$ & 2.22 & 3.92 \\
\hline 11 & $<\mathrm{DL}$ & $<\mathrm{DL}$ & 0.93 & 0.85 \\
\hline 12 & $<\mathrm{DL}$ & $<\mathrm{DL}$ & 0.85 & 1.43 \\
\hline 13 & $<\mathrm{DL}$ & $<\mathrm{DL}$ & 1.93 & 0.56 \\
\hline 14 & 0.63 & 0.70 & $<\mathrm{DL}$ & $<D L$ \\
\hline 15 & 2.54 & $<\mathrm{DL}$ & $<\mathrm{DL}$ & $<D L$ \\
\hline 16 & 1.46 & 0.52 & $<\mathrm{DL}$ & $<\mathrm{DL}$ \\
\hline
\end{tabular}

The results of bed (Table 2) show $\mathrm{Pb}, \mathrm{Cr}$ and $\mathrm{Cd}$ in all the establishments except 7 and 8. Its presence in manure may be related to its presence in feed. The accumulation in bed and leaving them on the floor could cause the contaminants reach the water table. As was not detected. 
Sustainability, Agri, Food and Environmental Research, 5(1), 2017: 17-24 ISSN: 0719-3726

Table 2. Trace element analysis of bed. Concentrations are expressed in $\mu \mathrm{g} / \mathrm{g}$.

$$
\text { BED }
$$

\begin{tabular}{ccccc}
\hline & $\mathrm{As}$ & $\mathrm{Cd}$ & $\mathrm{Cr}$ & $\mathrm{Pb}$ \\
$\mathrm{DL}$ & $<0.40$ & $<0.16$ & $<0.28$ & $<0.49$ \\
1 & $<\mathrm{DL}$ & 0.46 & $<\mathrm{DL}$ & 0.52 \\
2 & $<\mathrm{DL}$ & 0.63 & $<\mathrm{DL}$ & 1.01 \\
3 & $<\mathrm{DL}$ & 0.68 & 0.33 & 1.77 \\
4 & $<\mathrm{DL}$ & 0.65 & 0.47 & 0.99 \\
5 & $<\mathrm{DL}$ & 0.55 & 0.87 & 0.61 \\
6 & $<\mathrm{DL}$ & 0.74 & 0.85 & 0.62 \\
7 & $<\mathrm{DL}$ & 0.66 & $<\mathrm{DL}$ & $<\mathrm{DL}$ \\
8 & $<\mathrm{DL}$ & $<\mathrm{DL}$ & $<\mathrm{DL}$ & $<\mathrm{DL}$ \\
9 & $<\mathrm{DL}$ & 0.28 & 0.43 & 0.61 \\
10 & $<\mathrm{DL}$ & 0.43 & $<\mathrm{DL}$ & 0.78 \\
11 & $<\mathrm{DL}$ & 0.75 & $<\mathrm{DL}$ & 0.89 \\
12 & $<\mathrm{DL}$ & 0.53 & 0.91 & 0.67 \\
13 & $<\mathrm{DL}$ & 0.35 & 0.41 & 0.88 \\
14 & 0.57 & 0.45 & $<\mathrm{DL}$ & $<\mathrm{DL}$ \\
15 & 2.30 & $<\mathrm{DL}$ & $<\mathrm{DL}$ & $<\mathrm{DL}$ \\
16 & 2.30 & $<\mathrm{DL}$ & $<\mathrm{DL}$ & $<\mathrm{DL}$ \\
\hline
\end{tabular}

\section{CONCLUSIONS}

Analysis of the results show that bundles administered may be controlled since they may represent a risk for animal health, although until now there is no direct impact on the quality of groundwater. The fact that these establishments are $100 \%$ advised by veterinarians ensures early detection of possible symptoms of disease.

The deposit of waste bed outside the stables should be reviewed because it can leach residues of found materials and reach the water table or pollute surface water by runoff (Farías et al. 2003). The selection of feed ingredients could be a viable option to prevent possible contamination and protect the environment (Farías et al. 2003).

This survey has proven to be a good opportunity to assess some of the management practices, which may allow the improvement of management operations in equine production to preserve its sustainability.

\section{ACKNOWLEDGMENTS}

Authors are indebted to University of Buenos Aires and CONICET (National Scientific and Technical Research Council) for financial support.

\section{REFERENCES}

Asano R. Suzuki K. Otsuka T. Otsuka M. \& H. Sakurai. 2002. Concentrations of toxic metals and essential minerals in the main hair of healthy racing horses and their relation to age. Journal of Veterinary Medical Science 64: 607-610.

Auer A. Perez Carrera A. y A.V. Volpedo. 2013. Uso del agua en la producción de carne bovina. pp. 147-161. En: Fernández Cirelli A, Perez Carrera A, Volpedo, A, El agua en la producción Agropecuaria. Buenos Aires. 
Bott R.\&Greene E. 2013. Production and environmental implications of equine grazing.Journal of Equine Veterinary Science 33:1031-1043.

European Union.Directive 2002/32/EC of the European Parliament and of the Council on undesirable substances in animal feed. 2002. http://www.fediol.be/

Farías S. S. Casa V. A. Vázquez C. Ferpozzi L. Pucci G. N. y I.M. Cohen. 2003. Natural contamination with arsenic and other trace elements in ground waters of Argentine Pampean Plain. Science of the Total Environment. 309: 187-199.

Fernández Cirelli A. Volpedo. A.y Pérez Carrera A. 2013. La Calidad de Agua como Factor clave en la producción Animal. pp.11-38. En: Fernández Cirelli A, Perez Carrera A, Volpedo, A, El agua en la producción Agropecuaria. Buenos Aires

Fernández Cirelli A. Moscuzza H. Pérez Carrera A.y A.V. Volpedo. 2010. Aspectos ambientales de las actividades agropecuarias. Agrovet, Buenos Aires, $189 \mathrm{pp}$

Hainze M.T.M. Russell B.M. Wesley Wood C. McCall, C. y B. H. Wood. 2004. Faecal phosphorus excretion from horses fed tipical diets whith an without added phytase. Animal Feed Science and Technology 117:265-279

Ley 24051 Decreto 831/93 www.infoleg.gov.ar/infolegInternet/anexos/1000014999/12830/texact.htm

MINAGRI (2014). www.minagri.gob.ar

NRC. 2007. Nutrient requirements of horses. 7th Rev. ed. Washington, DC: National Academy Press.

Prokopy L.S. Perry-Hill R. y A.P. Reimer. 2011. Equine farm operators: an underserved target audience for conservation practice outreach? .Journal of Equine Veterinary Science 31: 447-55

SENASA .2015.www.senasa.gov.ar

Smedley P.\&D. Kinninburgh. 2002. A review of the source, behaviour and distribution of arsenic in natural waters. Applied Geochemistry 17: 517-568.

Swinker A.M.\& D.E. Johnson. 1995. Equine industries manure disposal practices, variations and magnitude.Animal Production Science. 11: 210-213.

Topliff D.R.\&G.D. Potter. 2002. Comparison of dry matter, nitrogen, and phosphorus excretion from feedlot steers and horses in race/performance training. Written testimony presented to the United States Environmental Protection Agency, Washington, DC.

Westendorf M.L Venkata P. Carey A.W. Troy J.\& R. Govindasamy. 2013. Dietary and Manure Management Practices on Equine Farms in Two New Jersey Watersheds. Journal of Equine Veterinary Science 33: 601-606

Westendorf, M.L., Joshua, T., Komar, S.J, Williams, C.,\& R. Govindasamy. 2010 a. Effectiveness of cooperative extension manure management programs. Journal of Equine Veterinary Science 30: 322-325.

Westendorf, M.L., Joshua, T., Komar, S.J., Williams, C. and R. Govindasamy. 2010 b. Manure management practices on New Jersey equine farms. Animal Production Science 26: 123-129.

Westerndorf, M.L. 2012. Environmetal Impacts of equine Operations: AU.S Departament of A Multiste Proyects agricultura. Journal of Equine Veterinary Science 32: 324-326. 